[RAdiocarbon, Vol 22, No. 2, 1980, P 250-259]

\title{
ON THE CLIMATE-RADIOCARBON RELATIONSHIP: NITRIC OXIDE AND OZONE AS CONNECTING LINKS BETWEEN RADIATION AND THE EARTH'S SURFACE TEMPERATURES
}

\author{
WALTER ROEDEL
}

Institut für Umweltphysik, University of Heidelberg, West Germany

\begin{abstract}
The correlations between atmospheric radiocarbon cencentrations, on the one hand, and solar activity and the earth's magnetic field, on the other, as well as possible relations between surface temperatures and solar activity and the earth's magnetic field are considered. To draw a consistent picture of these relations, the following mechanisms for climatic changes are proposed: The earth's magnetic field and solar activity both influence the fluxes of charged solar particles into the upper stratosphere; higher surface temperatures are positively correlated with higher particles fluxes. Charged particles produce nitric oxide, which controls, to some extent, the ozone destruction and, thus, the ozone inventory in the upper layers of the stratosphere (above the $10 \mathrm{mbar}$ level) in latitudes greater than about $60^{\circ}$. The varying ozone contents in the upper stratosphere affect the radiation balance and the temperatures on the earth's surface. It has been estimated that a reduction, or increase, respectively, of ozone in the layers above 10 mbar warms, or cools, respectively, the earth's surface. A change of ozone in the lower layers of the stratosphere has the opposite effect. The maximum net effect is in the order of $\Delta T_{s} \approx 0.3-1 \mathrm{~K}$, in both directions. This hypothesis might be in accordance with an orbital origin of long-term climatic changes.
\end{abstract}

\section{INTRODUCTION}

A simple unequivocal relationship between atmospheric radiocarbon concentrations and climate most probably does not exist. The coldest epoch known in historical times, for instance, the "Little Ice Age" during the 17 th and 18 th centuries, was accompanied by high radiocarbon levels as was the Sumerian warm epoch, about 6000 to 5000 BP (hypsithermal epoch, "climate optimum"). This ambiguity is not an unexpected one, because radiocarbon variations, too, have different causes (Suess, 1970).

This paper proposes a consistent relationship between varying ${ }^{14} \mathrm{C}$ production by cosmic rays and changes of the earth's surface temperatures, which allows for both factors controlling the flux of cosmic rays, the varying solar activity associated with varying interplanetary magnetic fields, and the varying dipole field of earth. In this study we will not consider variations of the ${ }^{14} \mathrm{C} /{ }^{12} \mathrm{C}$ ratio due to variations of the atmospheric carbon dioxide concentrations.

The existence of the two above mentioned causes of modulation of the ${ }^{14} \mathrm{C}$ production suggested we look for correlated climatic changes and for features common to both types of radiocarbon-climate relations. We found this common feature in the varying flux of charged solar particles, which is accompanied in both cases by varying surface temperatures in such a way that higher particle fluxes correspond to increased surface temperatures, and vice versa. Thereupon, we searched for a mechanism that might link varying solar particles radiation with changes of the earth's surface temperatures. We found that the variable production of nitric oxide by charged particles in the uppermost layers of the stratosphere, the varying ozone destruction by nitric oxide, and, finally, the influence of ozone on the atmospheric radiation budget might be this linking mechanism chain. The critical point within this chain is the sign of the relation between ozone and surface temperature. We estimated, 
however, that a decrease of ozone in the stratospheric layers above the 10 mbar level (due to an increase of particles radiation flux) warms the surface, and vice versa (whereas a change of ozone contents in the lower stratosphere has the opposite effect, as shown by Ramanathan, Callis, and Boughner, 1976).

\section{Radiocarbon-climate relations}

We will briefly reconsider the radiocarbon variations (for a detailed discussion the reader may refer to Olsson, 1970) and look for related climatic changes. As emphasized by Suess (1970) and by others, radiocarbon changes can be classified in long-term trends (due to variations of the earth's magnetic dipole field, with time scales of several thousand years) and in short-term variations (due to changes of solar activity, with time scales of some hundred years or even less), the latter often referred to as the DeVries effect.

In the upper part of figure 1 , the relative changes of atmospheric radiocarbon concentrations (as revealed by tree-ring measurements) versus the tree ring age, is shown; the solid line represents the long-term trend (data and regression curve according to Damon, Lerman, and Long, 1978; we have averaged Damon's data over each century). In the lower part of figure 1, the strength of the earth's magnetic dipole moment, $\mathrm{m}$, is plotted; the small bar and the dots represent measured values

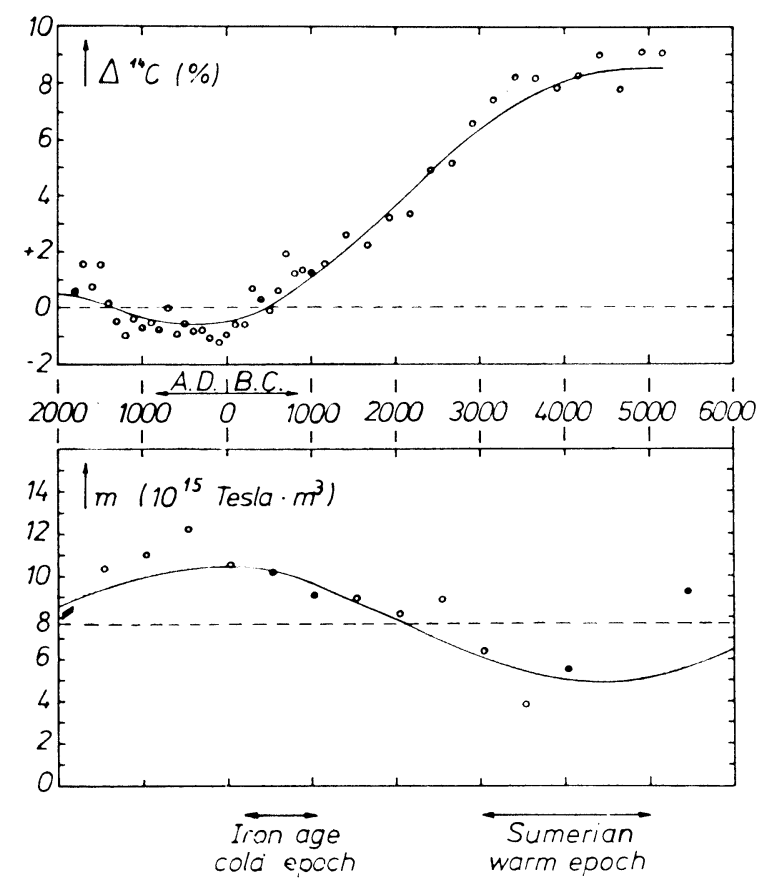

Fig 1. Long-term variations of radiocarbon (upper part) and corresponding changes of the earth's magnetic dipole moment (lower part). 
(Cox, 1968); the curve shows Bucha's (1970) sinoidal approximation. It is apparent that the magnetic dipole moment was low during the Sumerian warm epoch; when the magnetic dipole moment increased, the warm period was followed by quite a cold epoch in the last millennium BC (Iron age cold epoch, Gribbin and Lamb, 1978). The data are scarce, of course, but we will assume an anticorrelation between the earth's magnetic dipole moment and surface temperatures. In this case, we notice a positive correlation between radiocarbon concentration and surface temperatures.

The anticorrelation between temperature and magnetic field is not necessarily restricted to the very few historical data: Wollin, Ericson, and Wollin, (1974) have studied relations between the remnant magnetization of deep sea cores and corresponding $\mathrm{O}-16 / \mathrm{O}-18$ ratios for several $10^{5}$ years and found that the magnetization was high during ice ages and low during warm interglacials (though Wollin's interpretation of the data is not yet generally accepted, it has been suspected that the change of magnetization of deep sea cores might be due to changes of maritime chemistry caused by climatic changes).

To study the short-term variations, we have subtracted the long-term trend curve of figure 1 from the individual data. As a result, the upper part of figure 2 shows the short-term variations of ${ }^{14} \mathrm{C}$ during the last three millennia. As it has been shown for the first time by Stuiver (1961) and supported by other work (see, eg, Suess, 1970), ${ }^{14} \mathrm{C}$ production and solar activity are strongly anticorrelated. To intimate this relation, the bars in the middle part of figure 2 indicate qualitatively the periods with high or low solar activity.

In the lowest part of figure 2, Lamb's reconstruction of the mean prevailing temperatures over England during the last millennium BP is shown. The epochs of warm and cold climate in the past are indicated by bars in the middle part of figure 2 (see Gribbin and Lamb, 1978). It becomes apparent that high solar activities are accompanied by high surface temperatures, and vice versa. In accordance with former statements of Eddy (1977) we will assume that solar activity and ground-level temperatures are generally positively correlated. Consequently, an anticorrelation exists, in the short-term scale, between radiocarbon concentration and surface temperatures.

\section{The hypothesis of climatic change}

If we adopt the positive correlation between solar activity and temperature and the anticorrelation between the earth's magnetic field and temperature as being causal, the controlling quantity must be the varying flux of charged solar particles, primarily of solar protons. Solely charged particles are affected by magnetic fields. Furthermore, higher surface temperatures are associated with higher particles fluxes, which are either due to a decreased earth's magnetic field or to increased solar activity, and vice versa. Thus, the particles must originate from the sun, because the modulation of galactic particles by solar fields shows the wrong sign. 
Ionizing solar particles with energies above $30 \mathrm{MeV}$ (the threshold for coming down to the stratosphere) produce nitric oxide, NO, via the reactions

$$
\begin{array}{ll} 
& \mathrm{N}_{2}+\mathrm{e}^{-} \rightarrow \mathrm{N}+\mathrm{N}+\mathrm{e}^{-} \\
\text {(or also } & \left.\mathrm{N}_{2}+\mathrm{e}^{-} \rightarrow \mathrm{N}^{+}+\mathrm{N}+2 \mathrm{e}^{-}\right) \\
& \mathrm{N}+\mathrm{O}_{2} \rightarrow \mathrm{NO}+\mathrm{O}
\end{array}
$$

Nitric oxide partly controls the ozone destruction via the catalytic cycle

$$
\begin{array}{ll} 
& \mathrm{NO}+\mathrm{O}_{3} \rightarrow \mathrm{NO}_{2}+\mathrm{O}_{2} \\
& \mathrm{NO}_{2}+\mathrm{O} \rightarrow \mathrm{NO}+\mathrm{O}_{2} \\
\text { net } \quad & \mathrm{O}_{3}+\mathrm{O} \rightarrow 2 \mathrm{O}_{2}
\end{array}
$$

(the atomic oxygen being produced by photolysis of molecular oxygen). This controlling influence of solar protons on ozone in the upper layers of the stratosphere, above about $30 \mathrm{~km}$ altitude, is well established by the work of Crutzen, Isaksen, and Reid (1975), Heath, Krueger, and Crutzen (1977) and Fabian, Pyle, and Wells (1979).

Ozone absorbs solar radiation and thus affects the energy budget of the atmosphere and the surface temperature. We will discuss this last step in our chain separately in the next section. We will show that

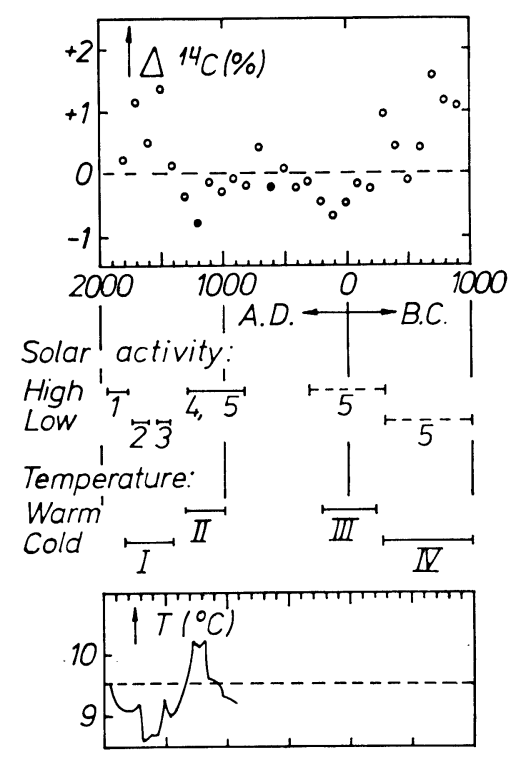

Fig 2. Short-term variations of radiocarbon, solar activity, and surface temperatures. Solar activity: 1) Modern maximum, 2) Maunder minimum, 3) Spörer minimum, 4) Medieval maximum (Shove, 1955), 5) Concluded from radiocarbon data. Temperatures: I. Little Ice age, II. Medieval warm epoch, III. Warm period during the Roman epoch, IV. Iron age cold epoch; the lowest curve represents Lamb's reconstruction of prevailing mean temperatures over England. 
decreasing ozone in the upper stratosphere warms the surface (and vice versa), in accordance with the requirement that increased particles fluxes are associated with increased temperatures on the surface.

With these mechanisms we may establish the causal chains sketched in figure 3: high solar activity, just as low magnetic field strength of earth, is accompanied with high fluxes of charged solar particles into the stratosphere, thus with a high nitric oxide production in the upper ozone layer and with a reduction of ozone in the upper stratosphere, and, finally, with an increased energy input and an increased temperature on the ground (and vice versa, of course).

The left-hand part of figure 3 represents the anticorrelation between radiocarbon and temperature in the time-scale of centuries, the right-hand part represents the positive correlation between radiocarbon and temperatures in the time-scale of millennia.

This hypothesis is undoubtedly speculative to some extent, but we feel it might be quite consistent. Too much faith may have been placed in the relations between climate and climate controlling factors, but we hope, that the presentation of the model is justified by its consistency rather than by an absolute certainty of its premises.

\section{Ozone-temperature relations}

The net effect of a change of ozone contents in the stratosphere on the earth's surface temperature is the result of a very delicate balance between the absorption of solar radiation, the re-emission of absorbed solar energy from the atmosphere, and the influence of ozone on the greenhouse effect (absorption and re-emission of terrestrial radiation). Generally, the lower the altitude in which ozone change takes place, the greater the influence of the re-emitted (long-wave) atmospheric radiation on the surface energy budget. Ramanathan, Callis, and Boughner (1976) have shown in a very careful study that a uniform decrease of ozone in the whole stratosphere even results in a net cooling of the surface.

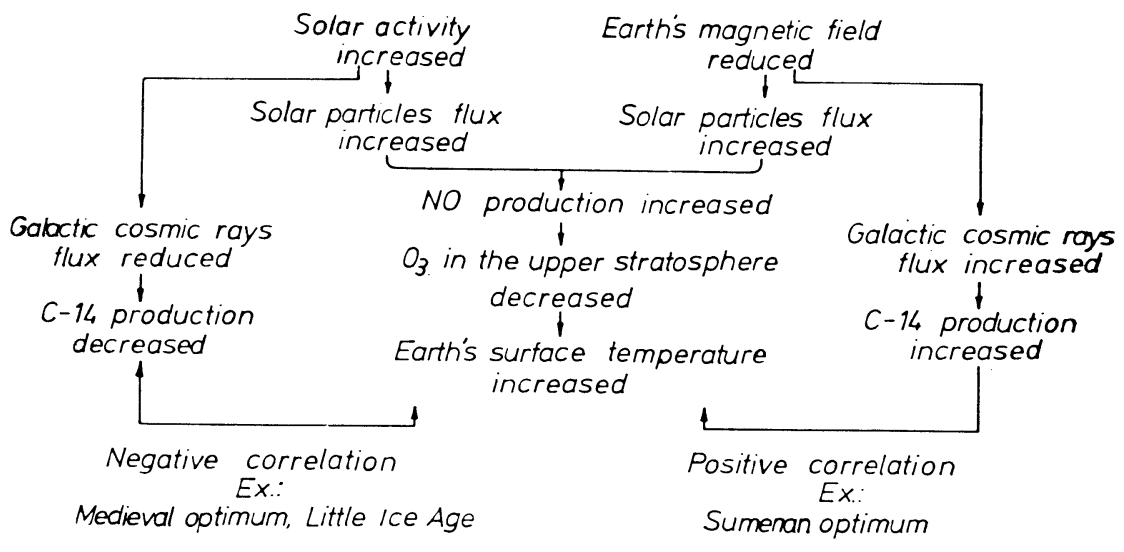

Fig 3. Schematic outline of causal chains. 
We have modified these considerations for the case that the variation of ozone is restricted to the uppermost layers of the stratosphere. To get a rough estimate we used a simple approximation: ozone is uniformly varied above the $10 \mathrm{mbar}$ level, but no change of ozone is assumed below this level. For calculating purposes, the atmosphere is divided in three sections, as shown in figure 4 ("high stratosphere", HS, above the 10 mbar level or about $30 \mathrm{~km}$ altitude, "main stratosphere", MS, from $10 \mathrm{mbar}$ down to 220 mbar or about $12 \mathrm{~km}$, and the "troposphere", T, below 220 mbar). After Dütsch (1978), we assume ozone amounts of $0.04 \mathrm{~cm} \mathrm{STP} \mathrm{in}$ HS (unperturbated case) and of $0.35 \mathrm{~cm}$ STP in MS (note that our model applies for latitudes above 50 to $60^{\circ}$ ). A zenith angle of $60^{\circ}$ is assumed. Figure 4 shows our results for the case of doubling the ozone contents in HS.

In the left-hand part of figure 4 the effects of ozone change on solar radiation are discussed. Absorption of solar radiation by ozone occurs primarily in the strong Hartley bands below $0.33 \mu \mathrm{m}$ wave-length, and in the Chappuis bands in the visible region between $0.42 \mu \mathrm{m}$ and $0.75 \mu \mathrm{m}$. In our estimate, we allow only for absorption by the weak Chappuis bands, because the response of the absorption by the Chappuis bands on ozone changes is nearly linear and, thus, very sensitive, whereas the energy absorption by the strong Hartley bands is deep in the saturation

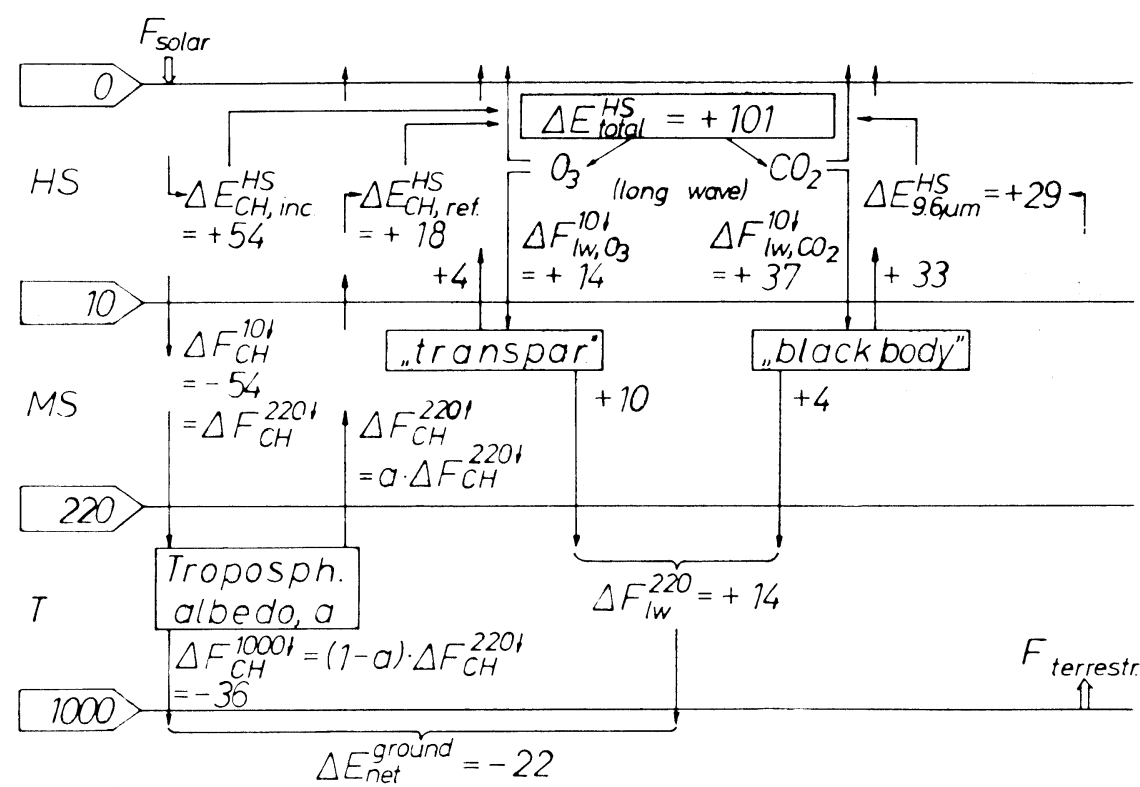

Fig 4. Estimated changes of energy fluxes $(\Delta \mathrm{F})$ and energy budgets $(\Delta \mathrm{E})$ due to ozone doubling above the $10 \mathrm{mbar}$ level; the unit is $\mu \mathrm{W} / \mathrm{cm}^{2}$. The numbers in the left-hand arrows mean millibar, HS, MS, and T mean "high stratosphere", "main stratosphere", and "troposphere", respectively. The numbers of $\mathbf{F}$ and $\mathbf{E}$, the result of a simple calculation, are not to be taken too literally. 
and not strongly dependent on ozone variations. To calculate the absorption of solar radiation we used the parametrization by Lacis and Hansen (1974). By doubling ozone in $\mathrm{HS}$ an additional energy $\Delta \mathbf{E}_{\mathrm{CH} \text {, inc }}=54$ $\mu \mathrm{W} / \mathrm{cm}^{2}$ is absorbed from the incident flux (the subscript $\mathrm{CH}$ means "Chappuis"). The flux towards the surface is decreased by this amount. But because of the tropospheric albedo, a (about 0.33), this decrease of the incident flux is shared between the flux upon the surface and the flux reflected towards the stratosphere and space. Because about one third of the total incident solar flux is reflected and penetrates HS a second time, additionally an energy of $18 \mu \mathrm{W} / \mathrm{cm}^{2}\left(\Delta \mathrm{E}_{\mathrm{CH}, \mathrm{ref}}\right)$ is absorbed in HS.

In the right-hand part of figure 4 the change of the "greenhouse effect" due to the $9.6 \mu \mathrm{m}$ vibration-rotation band of ozone is shown. The absorption of the $9.6 \mu \mathrm{m}$ band is parameterized in the paper of Ramanathan, Callis, and Boughner (1976). If ozone in HS is doubled, an additional energy of $\Delta \mathrm{E}_{9.6 \mu \mathrm{m}}=29 \mu \mathrm{W} / \mathrm{cm}^{2}$ is absorbed in HS. Thus, the total energy gain of HS by ozone doubling amounts to $101 \mu \mathrm{W} / \mathrm{cm}^{2}$, which has to be compensated by an increase of radiative cooling. Cooling is performed by emission of radiation from $\mathrm{CO}_{2}$ as well as from $\mathrm{O}_{3}$ (we used the parametrization by Dickinson, 1973). MS is quite transparent for radiation emitted by ozone, but not for radiation emitted from carbon dioxide, for which MS acts nearly as a "black body". The major part of the energy absorbed by $\mathrm{CO}_{2}$ is re-emitted into the space, only a small fraction (in our picture $4 \mu \mathrm{W} / \mathrm{cm}^{2}$ ) can penetrate down to the surface. Thus, by doubling ozone in HS, an additional energy flux of $14 \mu \mathrm{W} / \mathrm{cm}^{2}$ comes down to the earth's surface; this is not enough to balance completely the decrease of solar flux. The balance results in a net decrease of energy on the earth's surface of $-22 \mu \mathrm{W} / \mathrm{cm}^{2}$. The increase of ozone in $\mathrm{HS}$ cools the surface. Vice versa, of course, a decrease of ozone in HS warms the surface.

In view of the limits of ozone change given by the stratospheric chemistry (for a review see Johnston and Podolske, 1978) $\Delta \mathrm{E}$ net ground may range between $+25 \mu \mathrm{W} / \mathrm{cm}^{2}$ (maximum decrease of ozone by about $0.03 \mathrm{~cm} \mathrm{STP}$ ) and $-40 \mu \mathrm{W} / \mathrm{cm}^{2}$ (maximum increase of ozone in $\mathrm{HS}$ by about $0.06 \mathrm{~cm} S T P$ ). It is beyond the scope of this paper to compute a climate model giving proper account to these changes of radiation budgets. By comparison with existing models, however, in particular with the model of Manabe and Wetherald (1975) it can be estimated that $\mathrm{dT} / \mathrm{dE}$ on the ground is about $10 \mathrm{~K} / \mathrm{mW} \cdot \mathrm{cm}^{-2}$ at $65^{\circ}$ latitude and increases to about $20 \mathrm{~K} / \mathrm{mW} \cdot \mathrm{cm}^{-2}$ at $80^{\circ}$ latitude. Thus, the net effect of ozone changes due to the variation of solar particles flux might be in the order of 0.3 to $1.0 \mathrm{~K}$, in both directions from the present state, depending on latitude. This net effect might be amplified, of course, by mechanisms intrinsic to the system atmosphere-hydrosphere-earth's surface, for instance, by variation of the albedo of the surface. 
A remark on the orbital origin of ice ages

The model proposed here might also agree with an orbital origin of long-term climatic changes as confirmed by Hays, Imbrie, and Shackleton (1976). We mentioned the paleomagnetic measurements of Wollin, Ericson, and Wollin (1974), who found strong negative correlations between temperature and magnetization of sediments. Furthermore, Kent and Opdyke (1977) detected correlations between orbital parameters and magnetization and supposed that the variations of orbital parameters might trigger changes of the earth's magnetic field. Both interpretations, of course, are not entirely unambiguous; nevertheless, they might be correct. In this case, the mechanisms discussed here might be links between orbital parameters and climate, via the magnetic field of earth, in the sense that they might trigger larger changes in the system atmosphere-hydrosphere-surface, or synchronize terrestrial "oscillators", as, for instance, proposed by Flohn (1974).

\section{ACKNOWLEDGMENTS}

Part of this work was done at the University of Bern, where the author stayed as a guest of Hans Oeschger. Both the invitation as well as the stimulating discussions with Prof Oeschger are gratefully acknowledged. I am also indebted to many scientists for valuable criticism and useful suggestions: P J Crutzen, NCAR, Boulder, Colorado, P E Damon, University of Arizona, Tucson, C E Junge, MPI für Chemie, Mainz, B Lehmann, University of Bern, Minze Stuiver, University of Washington, Seattle, W Zdunkowski, University of Mainz, and E J Zeller, University of Kansas, Lawrence.

\section{REFERENCES}

Bucha, V, 1970, Influence of the earth's magnetic field on radiocarbon dating, in, Olsson, I U, ed, Radiocarbon variations and absolute chronology, Nobel symposium, 12th, Proc: New York, John Wiley \& Sons, p 501-511.

Cox, A, 1968, Length of geomagnetic polarity reversals: Jour Geophys Research, v 73, p $3247-3260$.

Crutzen, P J, Isaksen, I S A, and Reid, G C, 1975, Solar proton events: Stratospheric sources of nitric oxide: Science, $v$ 189, p 457-459.

Damon, P E, Lerman, J C, and Long, Austin, 1978, Temporal fluctuations of atmospheric ${ }^{14} \mathrm{C}$ : Causal factors and implications: Ann Rev Earth Planetary Sci, v 6, p 457-494.

Dickinson, R E, 1973, Method of parameterization for infrared cooling between altitudes of $30 \mathrm{~km}$ and $70 \mathrm{~km}$ : Jour Geophys Research, v 78, p 4451-4457.

Dütsch, H U, 1978, Vertical ozone on a global scale: Pageoph, v 116, p 511-529.

Eddy, J A, 1977, The case of missing sunspots: Scientific Am, v 236, p 80-92.

Fabian, P, Pyle, J A, and Wells, R J, 1979, The August 1972 solar proton event and the atmospheric ozone layer: Nature, v 277, p 458-460.

Flohn, H, 1974, Background of a geophysical model of the initiation of the next glaciation: Quaternary Research, v 4, p 385-404.

Gribbin, J and Lamb, H H, 1978, Climatic change in historical times, in, Gribbin, J, ed, Climatic change: Cambridge, Cambridge Univ Press, p 68-82.

Hays, J D, Imbrie, J, and Shackleton, N J, 1976, Variations in the earth's orbit: Pacemakers of the ice ages: Science, v 194, p 1121-1132.

Heath, D F, Krueger, A J, and Crutzen, P J, 1977, Solar proton event: Influence on stratospheric ozone: Science, v 197, p 886-889.

Johnston, H S and Podolske, J, 1978, Interpretations of stratospheric chemistry: Rev Geophys Space Physics, v 16, p 491-519.

Kent, D V and Opdyke, N D, 1977, Paelomagnetic field intensity variation recorded in a Brunhes epoch deep-sea sediment core: Nature, v 266, p 156-159. 
Lacis, A A and Hansen, J E, 1974, A parametrization for the absorption of solar radiation in the earth's atmosphere: Jour Atmospheric Sci, v 31, p 118-133.

Manabe, S and Wetherald, R T, 1975, The effects of doubling the $\mathrm{CO}_{2}$ concentration on the climate in a general circulation model: Jour Atmospheric Sci, v 32, p 3-15.

Olsson, I U, 1970, ed, Radiocarbon variations and absolute chronology, Nobel symposium, 12th, Proc: New York, John Wiley \& Sons, p 233-351.

Ramanathan, V, Callis, L B, and Boughner, R E, 1976 , Sensitivity of surface temperature and atmospheric temperature to perturbations in the stratospheric concentration of ozone and nitrogen dioxide: Jour Atmospheric Sci, v 33, p 1092-1112.

Shove, D J, 1955, The sunspot cycle 649 BC to 2000 AD: Jour Geophys Research, v 60, p $127-145$.

Sternberg, R S and Damon, P E, 1979, Sensitivity of radiocarbon fluctuations and inventory to geomagnetic and reservoir parameters, in Berger, Rainer and Suess, H E, eds, Radiocarbon dating, Internatl radiocarbon conf, 9th, Proc: Berkeley/Los Angeles, Univ California Press, p 691-720.

Stuiver, Minze, 1961, Variations in radiocarbon concentration and sunspot activity: Jour Geophys Research, v 66, p 273-276.

Suess, H E, 1970, The three causes of the secular ${ }^{14} \mathrm{C}$ fluctuations, their amplitudes and time constants, in Olsson, I U, ed, Radiocarbon variations and absolute chronology, Nobel symposium, 12th, Proc: New York, John Wiley \& Sons, p 595-606.

Wollin, G, Ericson, D B, and Wollin, J, 1974, Geomagnetic variations and climatic changes 2,000,000 вC - 1970 AD: Coll Intern CNRS, no. 219: Les méthodes quantitatives d'étude des variations du climat au cours du Pléistocene, p 273-288.

\section{DISCUSSION}

Barbetti: I want to challenge your claim for negative correlation between geomagnetic strength and temperature. Sternberg and Damon 1979 have demonstrated that earlier claims for such a correlation in 20th-century observatory records are not upheld by detailed statistical analysis. The late Pleistocene geomagnetic data from baked materials (which I presented yesterday) indicate a low dipole moment at the time of glacial maximum; so the correlation there is certainly not negative. The evidence suggests there is no simple correlation between dipole moment and temperature.

Roedel: I feel the data on the earth's magnetic field during the Late Pleistocene is still contradictory to some extent, but I admit that the data from deep sea sediments (which show the right sign) is not unambiguous. On the other hand I used, as premises for the hypothesis discussed, mainly the Holocene geomagnetic data.

Hartwig: Dr Roedel, I have very great difficulties with your conclusions. 1. The ozone cycle is governed not only by $\mathrm{NO}_{\mathrm{x}}$ as sinks (which may contribute at maximum 30 to 50 percent), but also by $\mathrm{ClO}_{x}, \mathrm{HO}_{\mathrm{x}}$, and downward diffusion as well. All chemical sinks are strongly interrelated by at least 80 chemical reactions (see Crutzen, Isaksen, and Reid, 1975). Therefore, it is difficult to forecast what is going to happen to any single reaction and concentration.

2. Ozone is photo-dissociated by UV-294 nm-radiation, which is only a very small part of the temperature determining a portion of the entire solar spectrum. Thus, the change in UV-radiation can have only a small effect. There might be some effect of stratospheric stability and circulation pattern as pointed out earlier, but one needs sophisticated models to calculate that.

3. The ozone problem is an entirely dynamic one. Therefore, I would hesitate to discuss any latitudinal dependency, (production and region 
of maximum concentration are separated remarkably) without a dynamic model.

Roedel: 1. Of course, we did not consider the $\mathrm{NO}_{\mathbf{x}}$ cycle only. We estimated the limits of ozone change within the framework of the reactions discussed by Johnston and Podolske. Furthermore, Fabian, Pyle, and Wells (1979) show that the present knowledge of stratospheric chemistry can properly describe the effects of solar particles; it is in full accordance with the mechanism chain predicted here.

2. The influence of an ozone change in the uppermost layers of the stratosphere on the radiation or energy budget is roughly estimated in the paper (it was omitted in the oral presentation).

3. This objection may be right. Nevertheless, we think that small changes of ozone do not appreciably affect the circulation patterns, but one cannot rule out such a change.

\section{REFERENCE}

Sternberg, R S and Damon, P E, 1979, Re-evaluation of possible historical relationship between magnetic intensity and climate: Nature, v 278, p 36-38. 